\title{
Effects of methyl jasmonate on the concentration of volatile terpenes in tissues of Maritime pine and Monterey pine and its relation to pine weevil feeding
}

\author{
Lina Lundborg $^{1}\left[\right.$ D $\cdot$ Luis Sampedro $^{2} \cdot$ Anna-Karin Borg-Karlson $^{1} \cdot$ Rafael Zas $^{2}$
}

Received: 1 August 2017 / Accepted: 28 August 2018 / Published online: 6 September 2018

(c) The Author(s) 2018

\begin{abstract}
Understanding pine weevil [Hylobius abietis (L.)] feeding preferences and their relations to chemical defenses of pines may lead to improved protection of conifer seedlings across Europe and Asia. Previous studies showed reduced weevil damage in methyl jasmonate (MeJA) treated seedlings and that weevil preference for Monterey pine (Pinus radiata Ait.) or Maritime pine (Pinus pinaster D. Don) depended on feeding conditions. The present study explored whether volatile terpenes in plant tissues of control and MeJA-treated seedlings of these two pine species could explain differences in weevil feeding and seedling growth. Volatile terpenes of hexane extracts of needles and phloem were separated and identified by gas chromatography-mass spectrometry (GC-MS). The results confirmed that MeJA application reduced pine weevil feeding in both pine species, but the increase in resistance was not explained by any general change in the concentration of mono- and sesquiterpenes after MeJA application. MeJA effects on volatile terpenes differed between the two pine species. Responses to MeJA application were more intense in Monterey pine, for which total mono- and sesquiterpenes were induced and growth rates affected, even at the lowest concentration of MeJA $(5 \mathrm{mM})$. In Maritime pine, seedling growth was affected only at the highest MeJA concentration $(25 \mathrm{mM})$, and no effect was observed on total volatile terpenes. Contrasting effects of MeJA on key monoterpenes were also observed. In needles, the content of (-)- $\beta$-pinene, a monoterpene with deterrent properties against the pine weevil, increased in MeJA-treated seedlings of Monterey pine, but not in Maritime pine. In the phloem of Maritime pine, the MeJA treatment reduced the concentration of the pine weevil attractant (+)- $\alpha$-pinene, whereas it was increased in Monterey pine. Altogether, results indicated that weevil preferences between the two species could be altered if resistance of seedlings were previously induced with MeJA. The differential inducibility of key volatile terpenes between the two pine species may be part of the explanation as to why pine weevil preferences to the two pine species differ between field and lab conditions.
\end{abstract}

Keywords Chemical defenses $\cdot$ Induced defenses $\cdot$ Plant-insect interaction $\cdot$ Forest pest

Communicated by Oßwald.

Electronic supplementary material The online version of this article (https://doi.org/10.1007/s00468-018-1757-1) contains supplementary material, which is available to authorized users.

Lina Lundborg

linalun@kth.se

1 Ecological Chemistry Group, Department of Chemistry, School of Engineering Sciences in Chemistry, Biotechnology and Health, KTH, Royal Institute of Technology, 10044 Stockholm, Sweden

2 Misión Biológica de Galicia, Consejo Superior de Investigaciones Científicas (MBG-CSIC), 36080 Pontevedra, Galicia, Spain

\section{Introduction}

Conifers are long lived species that have existed on Earth for millions of years (Schulman 1954). Single trees can live for hundreds or even thousands of years (Schulman 1954), and during their long life span, they cope with multiple herbivores and pathogens that feed on their tissues. To defend themselves, conifers have evolved a wide array of physical and chemical defenses (Franceschi et al. 2005). As in other plant groups, the defense chemicals of conifers are in part constitutive, i.e., present all the time, and in part induced, i.e., biosynthesized in response to the perception of a biotic stressor (Karban and Baldwin 1997). Terpenes and phenolics are the most important chemical defenses of 
conifers (Franceschi et al. 2005). Terpenes are stored in pine oleoresin, a viscous and toxic substance with strong protective properties (Phillips and Croteau 1999), and phenolics are biosynthesized and stored in the vacuoles of specialized parenchyma cells (Franceschi et al. 2005). Approximately half of the terpene content in the resin is of volatile nature (Lewinsohn et al. 1991). Volatile terpenes are known to largely influence insect orientation and herbivory, including feeding by the pine weevil, Hylobius abietis (L.) (Björklund et al. 2005; Heijari et al. 2005, 2011; Klepzig and Schlyter 1999), a major pest of young conifer seedlings across Europe and Asia (Långström and Day 2004).

The pine weevil causes serious problems for regeneration of conifer forest after clear cutting (Nordlander et al. 2011). Adults are attracted en masse by the volatile terpenes emitted from the stumps (Nordlander 1991). Weevils cause severe damage by feeding on the phloem and bark of the young conifer seedlings, naturally or artificially regenerated in the cleared area (Långström and Day 2004). New methods to protect conifer seedlings are needed because of environmental concerns over the use of insecticides (Nordlander et al. 2011). One potential new method is the elicitation of induced defenses by the application of chemical elicitors. The chemical elicitor methyl jasmonate (MeJA), a phytohormone involved in defense signalling of plants (Howe 2004), has shown particularly promising results. Its application on pine seedlings activates the seedlings' own induced defenses, reduces weevil damage and, ultimately, seedling mortality, as shown for several conifer species exposed to weevil attacks in field trials (Zas et al. 2014).

Maritime pine (Pinus pinaster Ait.) and Monterey pine (Pinus radiata $\mathrm{D}$. Don) are two widely planted pine species in Southern Europe that are heavily attacked by the pine weevil (Zas et al. 2006, 2008). Maritime pine is native to Southern Europe and Northern Africa, where the pine weevil naturally occurs, while Monterey pine was introduced from California and lacks a common evolutionary history with the pine weevil. Exogenous applications of MeJA induce terpene synthesis in the two species (Moreira et al. 2009) providing resistance against the pine weevil in bioassays (Sampedro et al. 2011) and under field conditions (Zas et al. 2014). Maritime and Monterey pine differ in resistance to the pine weevil (Carrillo-Gavilán et al. 2015; Zas et al. 2011). In bioassays the native species suffers greater damage than the exotic pine, but under field conditions the exotic pine is more heavily attacked (Zas et al. 2011). This variation in weevil preferences has been partly attributed to differences in the inducibility of pine chemical defenses: Maritime pine responds more strongly to weevil damage under field conditions, providing it with enhanced resistance compared to Monterey pine (Zas et al. 2011).

Volatile monoterpenes are main secondary compounds with important roles in weevil orientation and activity
(Björklund et al. 2005; Klepzig and Schlyter 1999), and their concentrations are largely responsive to biotic stimuli (Fedderwitz et al. 2016; Kovalchuk et al. 2015; Lundborg et al. 2016; Moreira et al. 2013). Monoterpenes emitted from seedlings work as attractants or deterrents, and may significantly influence weevils' decisions about what to feed on. The main monoterpenes in Maritime and Monterey pine are the (-)- $\beta$-pinene and the $\pm \alpha$-pinene (Moreira et al. 2013; Sampedro et al. 2010). (-)- $\beta$-Pinene acts as a deterrent to pine weevils (Lundborg et al. 2016), whereas $\alpha$-pinene is a key volatile in pine weevil orientation, attracting adult insects to oviposition or feeding sites (Nordlander 1990, $1991)$. The (-)- $\beta$-pinene is induced in the phloem and needles of conifer seedlings of both Maritime and Monterey pine in response to damage by the pine weevil (Moreira et al. 2013), and in Scots pine (Pinus sylvestris L.) and Norway spruce (Picea abies L. Karst.) in response to MeJA treatment (Lundborg et al. 2016). Little is yet known, however, about whether differences in the inducibility of these key monoterpenes may help explain weevil preferences across pine species.

Here we explored further whether differences in resistance to the pine weevil between control and MeJA-treated seedlings of the two species (Maritime and Monterey pine) could be explained by the concentrations of induced volatile monoterpenes. We also aimed to determine whether the contrasting patterns in weevil preference observed in field and lab conditions can be explained by differences in constitutive and induced concentrations of volatile monoterpenes. To this end, we analyzed volatile terpenes in tissues of control and MeJA-treated seedlings and differences in weevil damage in feeding bioassays.

\section{Materials and methods}

\section{Seedling material and treatments}

Seedlings of the two species were cultivated and treated with MeJA together with the seedling treatment-batches used in Zas et al. (2014). In summary, seeds of Maritime pine and Monterey pine collected from the Massif des Landes (France) and the coast of Asturias (Northwest Spain), respectively, were sown in August 2010 in containers in a commercial nursery in Pontevedra, Spain (NORFOR Nursery, $42.4333^{\circ} \mathrm{N}, 8.6333^{\circ} \mathrm{W}$ ). In June 2011 , when seedlings were around 8 -months-old, seedlings were treated with MeJA (Zas et al. 2014). In brief, solutions with 0, 5, 10 and $25 \mathrm{mM}$ of MeJA (Sigma-Aldrich ref 39924-52-2) were mixed in deionized water with $2.5 \%$ ethanol. Each seedling was sprayed twice with around $0.4 \mathrm{ml}$ of solution. The solutions were sprayed 27 days and 13 days before sampling and freezing of tissues for later chemical analysis. 
One set of seedlings was planted in the field on a recent clear-fell site to study growth, survival, resistance and tolerance to the pine weevil, and the corresponding results were published in Zas et al. (2014). For the present study, a subset of 20 randomly selected seedlings from each species $\times$ treatment combination was used for testing the effects of MeJA on weevil feeding rates by means of controlled bioassays in the greenhouse; and another similar subset was sampled for chemical analysis of volatile terpenes. The sample size of chemical analyses was 8-9 seedlings. In a few cases, where there were not enough seedlings, the sample sizes were reduced to three or five seedlings. Seedling material for chemical analysis was collected at the same time that the bioassays with pine weevils were performed.

Total height and stem diameter at the root collar were measured in all seedlings just before sampling or before the bioassays started, that is, 27 and 13 days after the first and second application of MeJA.

\section{Bioassays with pine weevils}

Pine weevil feeding was measured in bioassays similar to those described in Zas et al. (2011). In brief, each seedling was covered with a transparent polyethylene container and one pre-weighed pine weevil was confined within that container and allowed to feed on the seedling for $48 \mathrm{~h}$. Pine weevils were starved for $24 \mathrm{~h}$ before the start of the bioassays. The bark area consumed by the weevils was evaluated by measuring the lengths (in $\mathrm{mm}$ ) of the scars in two opposite axial transects of each seedling. The sum of these two lengths was used as a value of the weevil damage. Twenty seedlings of each species and MeJA treatment were used.

\section{Chemical analysis of volatiles}

\section{Tissue extractions}

Primary needles (4-6 depending on length) collected from the leader and a piece of basal stem (about 1-2 cm long) obtained from the main stem immediately above the root collar were directly frozen in liquid nitrogen and preserved at $-80^{\circ} \mathrm{C}$. The needle and phloem tissues were extracted at the Misión Biológica de Galicia (MBG-CSIC, Galicia, Spain). The extractions were made in $4 \mathrm{ml}$ glass-vials with $0.5 \mathrm{ml}$ of hexane containing $0.05 \mathrm{mg}$ pentadecane as internal quantitative standard (Sigma-Aldrich). After sonication (20 min) and subsequent extraction ( $24 \mathrm{~h}$ at room temperature), the extracts were transferred to $2 \mathrm{ml} \mathrm{GC}$-vials and transported to the Royal Institute of Technology (KTH, Stockholm, Sweden) by a refrigerated courier $\left(24 \mathrm{~h}\right.$ ship at $\left.-17{ }^{\circ} \mathrm{C}\right)$. Extracts were then stored in $\mathrm{a}-30{ }^{\circ} \mathrm{C}$ freezer until analysis using gas chromatography-mass spectrometry (GC-MS).
Standards of known conifer terpenes were prepared for reference and quantification. These were: $(+) /(-)-\alpha$-pinene, $(-)$ - $\beta$-pinene, $(+)$-3-carene, $\beta$-myrcene, $(+) /(-)$-limonene, terpinolene, linalool, bornyl acetate, $\beta$-caryophyllene, terpinene-4-ol, $\gamma$-elemene, $\alpha$-terpinyl acetate, $\alpha$-muurolene and $\alpha$-cadinol, all obtained from authentic samples and commercial sources.

\section{GC-GC-MS analysis of extracts}

Needle and phloem extracts were analyzed for \pm enantiomers of $\alpha$-pinene and $\beta$-pinene, using a method similar to Moreira et al. (2013). The GC-GC-MS Agilent system consisted of two 7890A GCs, each coupled to a 5975C MS. Injection was splitless, purge time $0.5 \mathrm{~min}$, at an injector temperature of $240^{\circ} \mathrm{C}$. Injection volume was $1 \mu \mathrm{l}$ and carrier gas was helium at 34 psi. In the first GC, a DB-5 capillary column $(30 \mathrm{~m}$, i.d. $0.25 \mathrm{~mm}$, film thickness $0.25 \mu \mathrm{m}$, Agilent) was installed. The oven program of the first GC was isothermal at $40{ }^{\circ} \mathrm{C}$ for $0.1 \mathrm{~min}$, and then the temperature was increased with a rate of $10{ }^{\circ} \mathrm{C} \mathrm{min}{ }^{-1}$ up to $270{ }^{\circ} \mathrm{C}$, kept isothermal for $0.1 \mathrm{~min}$, and then increased by $100{ }^{\circ} \mathrm{C} \mathrm{min}-1$ to $300{ }^{\circ} \mathrm{C}$, isothermal for $1 \mathrm{~min}$.

In the second GC a Cyclodex- $\beta$ capillary column ( $30 \mathrm{~m}$, i.d. $0.25 \mathrm{~mm}$, film thickness $0.25 \mu \mathrm{m}$; Agilent) was installed. The column oven program was kept at $55{ }^{\circ} \mathrm{C}$ for $0.1 \mathrm{~min}$, then raised at a rate of $1{ }^{\circ} \mathrm{C} \mathrm{min}-1$ to $78^{\circ} \mathrm{C}$, kept isothermal

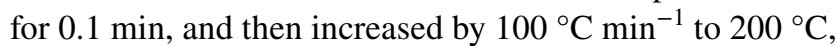
and kept for $1 \mathrm{~min}$. For the transfer from the first GC to the second $\mathrm{GC}$, a temperature program was used starting at $50{ }^{\circ} \mathrm{C}$ for $10 \mathrm{~min}$, and then increased to $130{ }^{\circ} \mathrm{C}$ by $10^{\circ} \mathrm{C}$ $\min ^{-1}$. The final temperature was kept isothermal for $8 \mathrm{~min}$.

The relative amounts of \pm enantiomers of $\alpha$-pinene and $\beta$-pinene were determined procentually on the second GC-MS result, on extracted ion chromatogram of $\mathrm{m} / \mathrm{z}$ 93, and absolute amounts determined from quantitative results for respective tissue.

\section{GC-MS analysis of needle extracts}

Quantitative results of mono- and sesquiterpenes, and volatile aromatics, for needle extracts were received at the same time as GC-GC-MS analyses were performed. Mass range on the first GC was set to $35-350 \mathrm{~m} / \mathrm{z}$. Integration was performed on the total ion chromatogram (TIC). Putative identifications of unknown compounds were made using NIST Mass Spectral Library matches in G1701EA MSD ChemStation software (Agilent Technologies, CA, USA).

\section{GC-MS analyses of phloem extracts}

The mono- and sesquiterpenes present in the phloem extracts were separated and quantified using a Varian 3400 
GC connected to a Finnigan SSQ 7000 MS instrument. Injection was splitless, purge time $0.5 \mathrm{~min}$, at an injector temperature of $230{ }^{\circ} \mathrm{C}$. Injection volume was $1 \mu \mathrm{l}$ and the carrier gas was helium at a pressure of 15 psi. The GC oven was equipped with a DB-WAX fused silica capillary column ( $30 \mathrm{~m}$, i.d. $0.25 \mathrm{~mm}$, film thickness $0.25 \mu \mathrm{m}$; Agilent). The temperature program was $40^{\circ} \mathrm{C}$ for $3 \mathrm{~min}$, then increased by $4{ }^{\circ} \mathrm{C} \mathrm{min}^{-1}$ up to $235^{\circ} \mathrm{C}$. The final temperature was kept isothermal for $18 \mathrm{~min}$ to allow the diterpene acids to elute before starting the analysis of the next sample. To improve the detection limit for the mono- and sesquiterpenes, the MS was operated in single ion monitoring (SIM) mode to scan for known terpene fragments of mass to charge ratios $m / z 68,69,77,93,121,136,161,204$, 222,272 , and the pentadecane standard with the fragment $\mathrm{m} / \mathrm{z} 212$. For the phloem samples, the quantification of terpenes was made upon reference standard curves, without including the pentadecane fragment which was very small.

\section{Chemical analysis of non-volatile resin}

The concentration of non-volatile resin, which is highly correlated with the diterpene fraction of the oleoresin (Sampedro et al. 2011), has been previously related with weevil damage (higher concentrations associated to reduced weevil damage; Zas et al. 2014) and is known to be highly responsive to both MeJA application (Moreira et al. 2009; Zas et al. 2014) and weevil feeding (Moreira et al. 2013; Sampedro et al. 2011). In addition to direct increases of chemical defenses, biotic stimuli could also induce a physiological plant state called 'priming' in which the defensive molecular machinery is preactivated so that the plants are able to react faster or stronger to following biotic challenges (Conrath et al. 2006). This intermediate state has been demonstrated in many different plant species, including conifers (Zhao et al. 2011). To determine whether MeJA treatments increased the chemical responses of the pine seedlings to subsequent weevil feeding (i.e., priming) (Conrath et al. 2006), both the seedlings used for volatile analyses and the seedlings used for the feeding bioassays were analyzed for their content of non-volatile resin.

Non-volatile resin was determined gravimetrically in phloem tissues after extraction with hexane in an ultrasonic bath for $15 \mathrm{~min}$ at $20^{\circ} \mathrm{C}$ and then for $24 \mathrm{~h}$ at room temperature. The extracts were then filtered (Whatman GFF, Whatman Int. Ltd., Maidstone, Kent, UK) and the extraction repeated again. The solvent in the extracts was evaporated to dryness and the mass of the non-volatile resin residue was determined to the nearest $0.0001 \mathrm{~g}$ and expressed as $\mathrm{mg}$ of non-volatile resin $\mathrm{g}^{-1}$ dried weight (dw).

\section{Statistical analysis}

For the biological data of plant growth and weevil wounds in the bioassays, two-way ANOVAs were made with the main factors of pine species, the MeJA treatments, and their interaction. In the case of the pine weevil wounds, the statistical model also included the individual pine weevil weights and the diameter of the seedlings as covariates. The analyses were performed in SAS (Statistical Analysis Software, Cary, NC, USA).

For the chemical data of total mono- and sesquiterpenes and main volatile terpenes, similar ANOVA models were used. Needles and phloem were analyzed separately. All available replicates were included in the statistical analyses. The descriptive statistics were untransformed least square means with standard errors (SE). Specific contrasts among MeJA treatments within each species were carried out within the two-way ANOVAs using Tukey's multiple comparison adjustments. Before the statistical tests the data was logarithmically transformed to normalize distributions.

The effect of MeJA, weevil feeding and their interaction on the concentration of non-volatile resin in the phloem was analyzed with a two-way ANOVA carried out independently for each pine species. A significant MeJA× weevil interaction would reflect a priming effect of MeJA.

\section{Results}

\section{Plant growth}

The MeJA treatments decreased seedling height growth in both Maritime and Monterey pine (Fig. 1). The diameter of the conifer seedlings were, however, not affected by the MeJA treatments (Table S1). The effect of MeJA treatments on height differed between the two species (Fig. 1). In Maritime pine only the strongest MeJA concentration $(25 \mathrm{mM})$ caused a significant reduction in growth rate, whereas in Monterey pine the reduction was similar for all MeJA concentrations (Fig. 1). The Maritime pine seedlings were slightly taller than the Monterey pine seedlings, but seedlings of the two pine species did not differ in diameter (Table S1).

\section{Pine weevil feeding in the bioassays}

Weevils consumed more phloem on Maritime pine than on Monterey pine (Fig. 2, Table S2). MeJA application clearly reduced pine weevil feeding in the two pine species with a dose-dependent response. The highest MeJA concentrations reduced weevil feeding by more than $50 \%$ compared to the control seedlings. The protective effect of MeJA was similar 


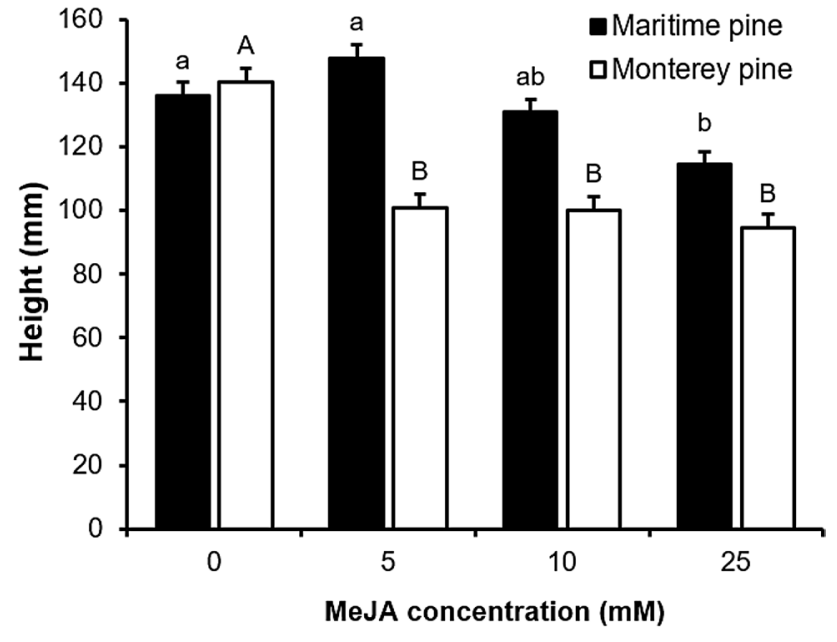

Fig. 1 Total height of pine seedlings one month after application of methyl jasmonate (MeJA) on the foliage. Bars represent mean \pm SE. $N=20$. Bars with different letters denote significant differences among MeJA treatments for each species $(p<0.05)$ after two-way ANOVA analysis

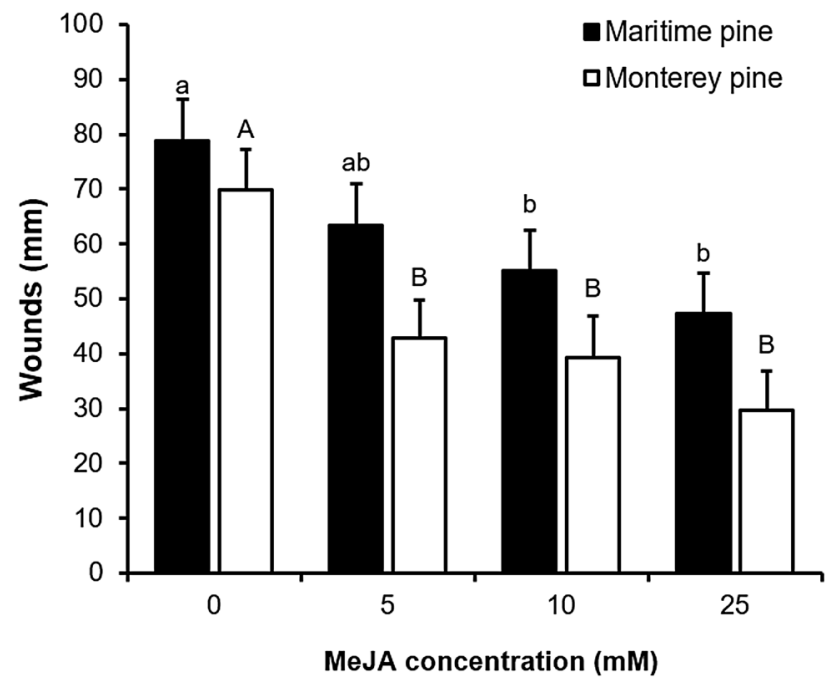

Fig. 2 Pine weevil damage (feeding wounds) on the stem of pine seedlings sprayed with different concentrations of methyl jasmonate (MeJA). One adult weevil was allowed to feed in each seedling for $48 \mathrm{~h}$. Wounding is presented in $\mathrm{mm}$ as it was estimated with longitudinal transects. The bars represent mean \pm SE. $N=20$ seedlings per MeJA $\times$ species combination. Bars with different letters denote significant differences $(p<0.05)$ for each species after two-way ANOVA analysis

for both pine species (no significant interaction). However, while in Monterey pine all treatments significantly reduced weevil feeding relative to control seedlings, in Maritime pine, significant effects were only observed for the 10 and $25 \mathrm{mM}$ MeJA treatments (Fig. 2).
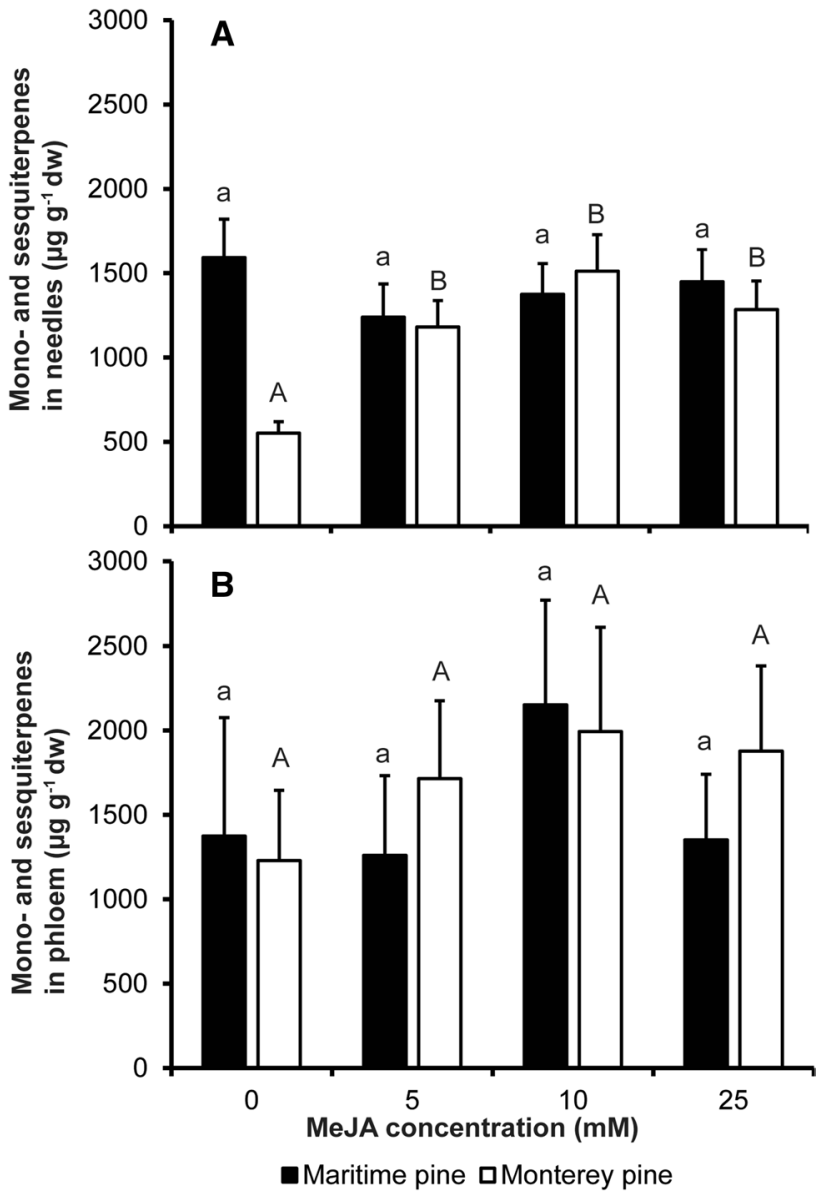

Fig. 3 Contents of total mono- and sesquiterpenes in needles $(N=5-9)$ and phloem $(N=3-9)$ of seedlings of Maritime and Monterey pine treated with methyl jasmonate (MeJA) concentrations $(0,5$, 10 and $25 \mathrm{mM}$ ). Bars show mean and standard error (SE). Bars with different letters denote significant differences $(p<0.05)$ for each species after two-way ANOVA analysis

\section{Volatiles}

MeJA treatment significantly affected the amounts of the total mono- and sesquiterpenes in the needles of the pine seedlings but not those in the phloem (Fig. 3, Table S3). The effect of MeJA on needle total volatile terpenes differed, however, between the two species (significant interaction, Table S3), being only significant for Monterey pine (Fig. 3a). Even with the weakest MeJA treatment (5 mM), the total mono- and sesquiterpenes increased in the needles of Monterey pine, with no further differences between the 5, 10 and $25 \mathrm{mM}$ MeJA treatments (Fig. 3a). In contrast, in the needles of Maritime pine, the MeJA treatments did not alter the amounts of total mono- and sesquiterpenes (Fig. 3a). In needles, the control seedlings of Maritime pine contained higher amounts of total mono- and sesquiterpenes than those of Monterey pine. After MeJA treatment, the 
seedlings of Monterey and Maritime pine were, however, at a similar level (Fig. 3a).

For all individuals of both pine species and tissues, monoterpenes constituted approximately $90 \%$ of the relative amounts of the volatile compounds, with the groups of sesquiterpenes and oxygenated monoterpenes in minor amounts (Tables S5-S8). The dominating monoterpenes were the $(-) /(+)-\alpha$-pinene and the $(-)-\beta$-pinene. MeJA treatment had contrasting effects on these main monoterpenes depending on the species and the tissue (Table S4). In needle tissues, MeJA application increased the amounts of the abundant monoterpene (-)- $\beta$-pinene, but the effect strongly differed between the two species (significant species $\times$ MeJA interaction, Table S4). In needles of Monterey pine the amounts of (-)- $\beta$-pinene increased in seedlings of all MeJA treatments, compared to control seedlings, while no effect was observed in the needles of Maritime pine (Fig. 5a).

In the phloem of both Maritime and Monterey pine, total mono- and sesquiterpenes did not increase with the MeJA treatments (Fig. 3b, Table S3). However, concentrations of specific monoterpenes were modified by the MeJA treatments. In the needles of Monterey pine the aromatic volatile estragole responded to increased MeJA concentration (Fig. 4; see details for all identified compounds in Tables S9-S12). In the phloem of Maritime pine the concentration of the monoterpene hydrocarbon (+)-3-carene, was higher in MeJA treated seedlings (Table S11) but the increase was not significant.

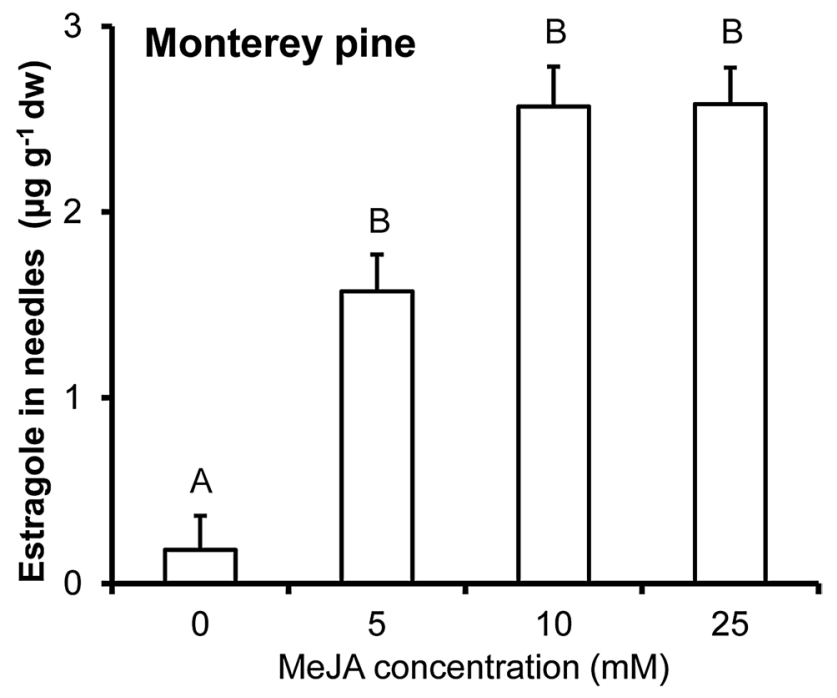

Fig. 4 Contents of estragole in needles $(N=6-8)$ of seedlings of Monterey pine treated with methyl jasmonate (MeJA) concentrations $(0,5,10$ and $25 \mathrm{mM})$. Bars show mean and standard error (SE). Bars with different letters denote significant differences $(p<0.05)$ for each species after two-way ANOVA analysis
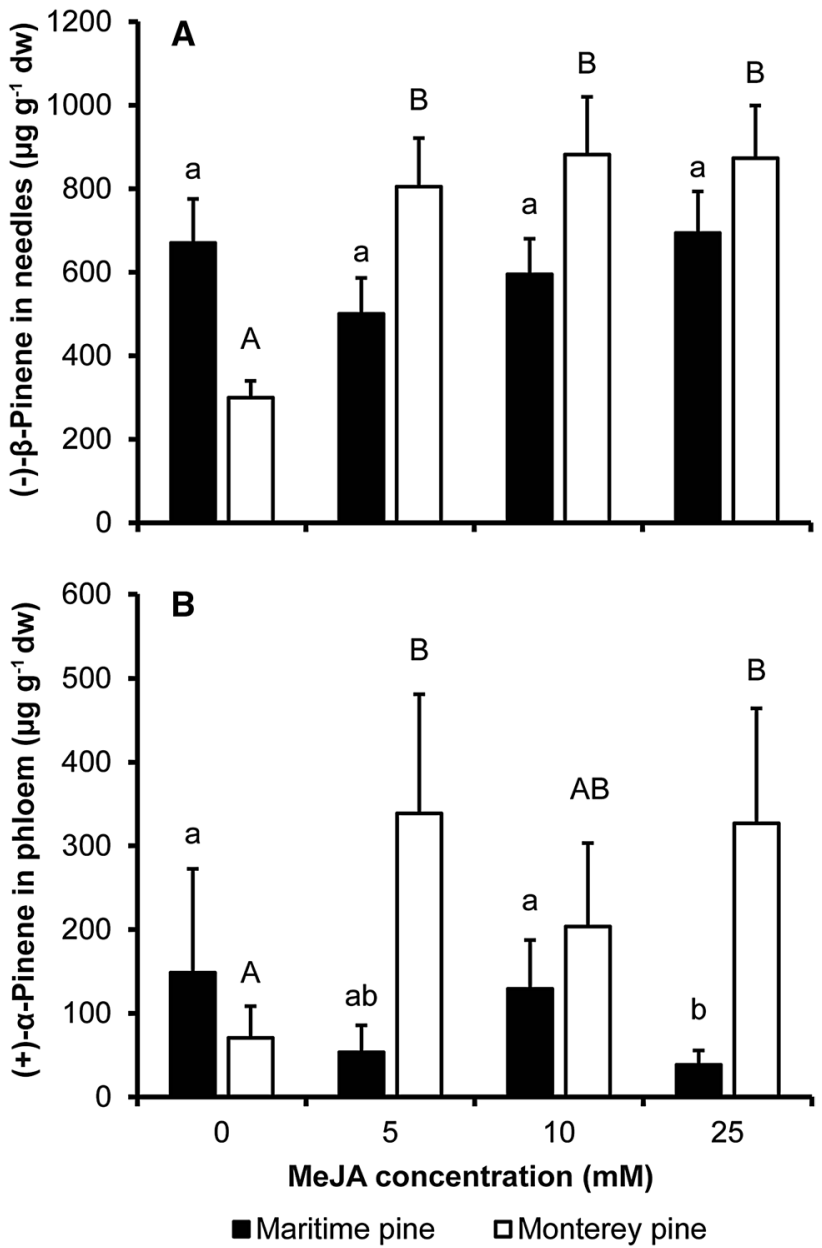

Fig. 5 Contents of (-)- $\beta$-pinene in the needles $(N=5-9)$ and $(+)-\alpha$-pinene in the phloem $(N=3-9)$ of seedlings of Maritime and Monterey pine treated with different methyl jasmonate (MeJA) concentrations $(0,5,10$ and $25 \mathrm{mM})$. Bars show mean and standard error (SE). Bars with different letters denote significant differences $(p<0.05)$ for each species after two-way ANOVA analysis

For the phloem contents of (+)- $\alpha$-pinene, species identity was significant, and there was a significant interaction between the species and the MeJA treatment (Table S4). Thus, the absolute amounts of (+)- $\alpha$-pinene in the phloem of the two pine species were affected differently by the MeJA treatment. The treatment with the highest concentration $(25 \mathrm{mM})$ decreased the amounts of $(+)$ - $\alpha$-pinene in Maritime pine (marginally significant), but increased those of Monterey pine (significant) (Fig. 5b).

\section{Non-volatile resin}

Both MeJA treatments and weevil feeding increased the concentration of non-volatile resin in the phloem in the two pine species (Fig. 6). The response to weevil feeding was, however, statistically similar for all MeJA treatments (no 

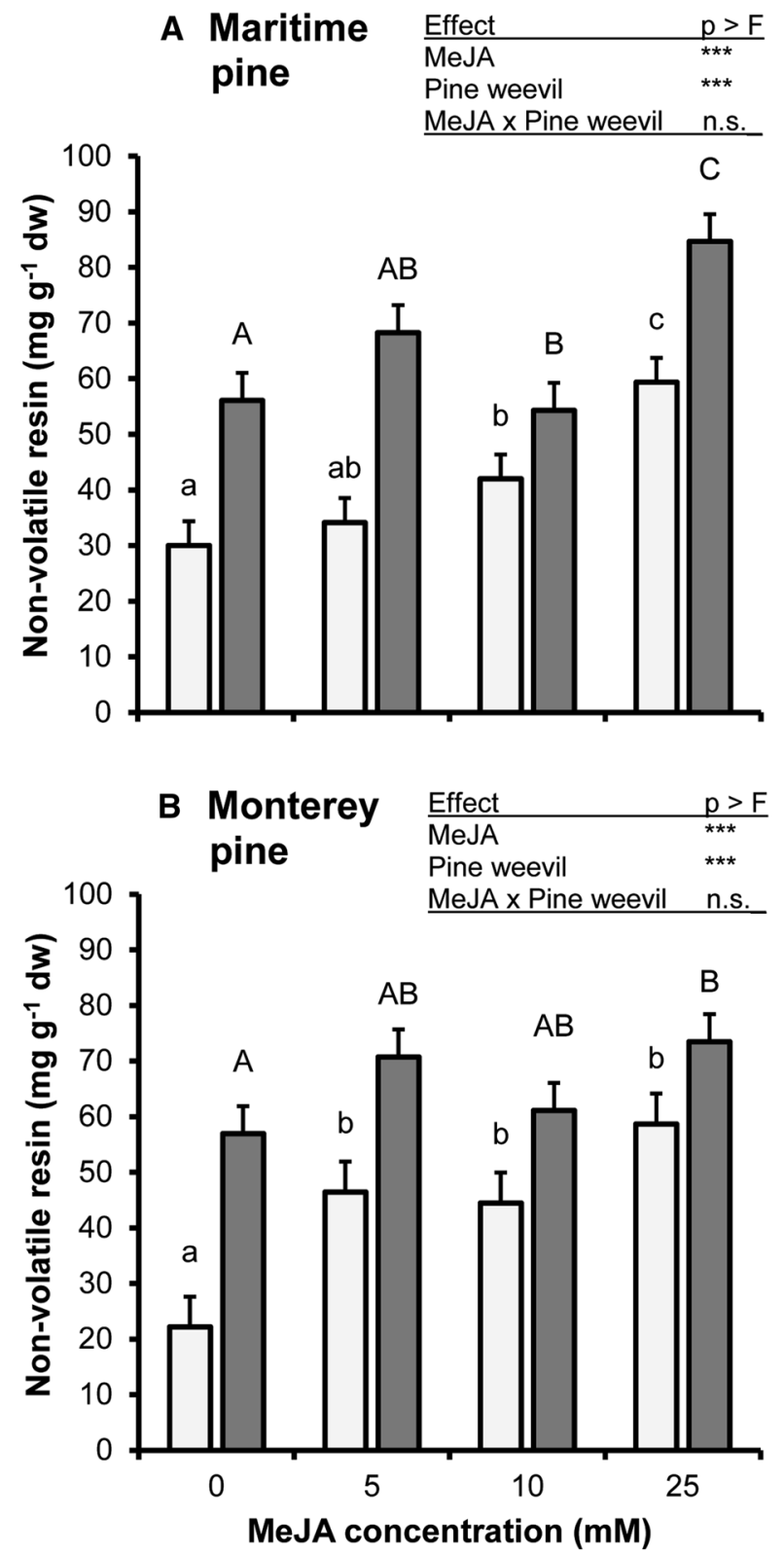

口Before weevil feeding

口After weevil feeding

Fig. 6 Concentration of non-volatile resin in the stems of a Maritime pine and b Monterey pine seedlings treated with different methyl jasmonate (MeJA) concentrations $(0,5,10$ and $25 \mathrm{mM})$ and subsequently exposed or not to weevil feeding for $48 \mathrm{~h}$. Bars show mean and standard error (SE) $(N=20)$. Bars with different lower and uppercase letters denote significant differences $(p<0.05)$ among MeJA concentrations before and after weevil feeding, respectively. Companion tables report the significance of the responses to weevil feeding, MeJA application and their interaction $(* p<0.05 ; * * p<0.01$; $* * * p<0.001 ; n s$ no significant)

significant MeJA $\times$ Weevil interaction; $F_{3,64}=1.87, p=0.143$ for Maritime pine and $F_{3,80}=1.52, p=0.216$ for Monterey pine) (Fig. 6).

\section{Discussion}

\section{MeJA effects on volatile terpenes and weevil feeding}

MeJA treatment clearly reduced phloem feeding by the pine weevil on both Maritime and Monterey pine. Previous environmentally controlled bioassays support this short-term protection by MeJA (Moreira et al. 2009; Sampedro et al. 2011). MeJA seedlings from the same treatment-batches as in the present study, were also protected in the field (Zas et al. 2014).

A few studies have analyzed volatile terpene contents (Heijari et al. 2005; Lundborg et al. 2016; Moreira et al. 2013) and emissions (Heijari et al. 2011) of conifer tissues in relation to pine weevil feeding damage. In the present study, however, we analyzed the effect of previous MeJA treatments on terpene contents, trying to relate the changes in terpene concentrations by MeJA to the reduction of pine weevil feeding damage observed in bioassays (Moreira et al. 2009; Sampedro et al. 2011) and in the field (Zas et al. 2014). We found no clear relationship between the effect of MeJA on mono- and sesquiterpene concentrations in the phloem and the strong and consistent increase in resistance against the pine weevil observed in both pine species. Concentrations of terpenes in the phloem, the tissue on which the pine weevils feed on, were only slightly modified by MeJA, and the few and small observed changes largely differed between the two pine species (see discussion below).

In phloem of Maritime pine, MeJA treatment increased the (+)-3-carene, which is a pine weevil deterrent (Lundborg et al. 2016), and in needles of Monterey pine, MeJA treatment increased the volatile estragole, which is a pine weevil antifeedant (Klepzig and Schlyter 1999). As there are very small amounts of these compounds in the phloem, and the effects of MeJA on their concentration largely differed between the two pine species, the increase in resistance against the pine weevil after MeJA application might be related to additional effects of MeJA on the seedling defenses.

Two alternative processes may explain the protective effect of MeJA. On the one hand, MeJA is known to increase other resistance traits in phloem tissues such as non-volatile resin and total phenolics (Heijari et al. 2005; Moreira et al. 2009; Schiebe et al. 2012; Zas et al. 2014). The parallel between the increase of these defensive traits in the phloem and the reduction in weevil feeding rate after MeJA application suggests a relevant role of these traits in seedling resistance against this insect (Zas et al. 2014). On the other hand, rather than a direct boost of chemical defenses, the effect of MeJA could be related to a priming effect (Conrath et al. 2006), by which MeJA-treated seedlings would be able to 
react faster or more vigorously to subsequent pine weevil feeding. The enhancement of the pine responses to weevil feeding in MeJA-treated seedlings would thus be responsible for their increase in resistance. This phenomenon has been shown to occur in other conifer species after MeJA application (e.g., Zhao et al. 2011) and could be also operating here. Testing this hypothesis would require knowing the terpene concentrations in control and MeJA-treated seedlings after weevil feeding, but, unfortunately, we lack this information. Nevertheless, weevil-exposed seedlings were analyzed for the concentration of non-volatile resin in the stem. In agreement with previous results, non-volatile resin notably increased in response to both MeJA application (Moreira et al. 2009; Zas et al. 2014) and weevil feeding (Moreira et al. 2013; Sampedro et al. 2011). The results indicated, however, that the increase in non-volatile resin in response to pine weevil feeding was not altered by the previous application of MeJA. The hypothesis of a MeJA-driven priming is thus not supported by our results. Further research is needed, however, to confirm whether this is also the case for volatile terpenes and other chemical defenses.

\section{Weevil feeding preferences}

Pine weevils fed significantly more on Maritime than on Monterey pine in the bioassays. In concordance with this result, previous studies have shown that the pine weevils prefer Maritime pine over Monterey pine when cut twigs are offered in Petri dishes (Zas et al. 2011). However, in field experiments, previous studies have shown a clear preference of the pine weevils for Monterey pine (Zas et al. 2011). Differences in the levels of weevil damage between field and laboratory conditions have been explained before in terms of different capabilities to elicit induced responses (Zas et al. 2011). The response or the effectiveness of the response of the exotic species, the Monterey pine, to the pine weevil has been shown to be lower than that of the native Maritime pine (Zas et al. 2011). While the pine weevil initially prefers Maritime pine over Monterey pine, the greater inducibility of the former can switch weevil preferences whenever there is enough time for induced defenses to impact weevil activity (Zas et al. 2011). Pine weevil preferences between the two pine species would, thus, depend on the effectiveness of the induced responses during the course of the experimental bioassays (Zas et al. 2011).

In the present study, pine weevils consumed more Maritime than Monterey pine, suggesting that the $48 \mathrm{~h}$ experimental feeding period used in the bioassays was not enough for establishing differences in weevil feeding due to differences between the two pine species in their ability to elicit induced responses. Indeed, responses to weevil feeding increasing the concentration of non-volatile resin in the stems were fairly similar between the two pine species. We speculate that longer feeding periods, however, could allow differences between the two pine species in the extent to which induced defenses deter weevil feeding, switching the preferences of the pine weevils towards the exotic species. Additionally, differences in weevil damage between the two species could be altered by the previous MeJA treatments, distorting the role of weevil-induced responses on weevil preferences (see discussion below).

\section{MeJA responses differed between the two pine species}

We found changes in the composition of volatile contents of tissues, in both Maritime pine and Monterey pine, after MeJA application, but the effects differed between the two species. Results from the present study suggest that differences in constitutive and inducible volatile terpenes after MeJA application may help explain why both species are attacked differently in the field compared with short-term laboratory experiments in which weevils are not allowed to choose where to feed. In Maritime pine, the amounts of $(+)-\alpha$-pinene in the phloem decreased after MeJA application, whereas it increased in Monterey pine. These results may affect the behaviour of pine weevils in the field, as $\alpha$-pinene is known to be important for pine weevil orientation (Nordlander 1990; Wibe et al. 1998). Nordlander (1990) found $(+) /(-)-\alpha$-pinene to be attractant to pine weevils in baited pitfall traps while Wibe et al. (1998) described a pine weevil antennal receptor that was more tuned to the $(+)$-enantiomer than to the (-)-enantiomer of $\alpha$-pinene. Accordingly, Lundborg et al. (2016) found no effect of $(-)-\alpha$-pinene in orientation bioassays with pine weevils. Assuming an attraction role of $\alpha$-pinene to pine weevils, the differences observed between the two species suggest that, once induced, Monterey pine seedlings may be more attractive for the weevils, as they produce more (+)- $\alpha$-pinene than the seedlings of Maritime pine. This hypothesis agrees with previous findings, showing more damage by the pine weevils on Monterey than on Maritime pine when weevils are allowed to choose between the two species, as occurs in the field (Zas et al. 2011).

On the other hand, the (-)- $\beta$-pinene is known to have antifeedant properties against the pine weevil (Klepzig and Schlyter 1999), and a negative effect on the orientation towards pine twigs (Lundborg et al. 2016). Control needles of Maritime pine and Monterey pine seedlings differed in the amounts of $(-)-\beta$-pinene with needles of Monterey pine containing significantly lower amounts of $(-)-\beta$-pinene than those of Maritime pine. However, MeJA differentially altered the amount of (-)- $\beta$-pinene in needles depending on the pine species (significant MeJA by species interaction), increasing the absolute amounts in Monterey pine needles to the same level as those of Maritime pine needles, which were 
not affected by the MeJA treatments. These results indicate that the differences in weevil preferences between the two species could be significantly altered if seedlings were previously induced with MeJA.

\section{Conclusions}

Our results confirmed that MeJA application reduced pine weevil feeding on seedlings of the two pine species as measured in non-choice bioassays, evidencing increased effective resistance. This increase in resistance was not explained by any general change in the concentration of mono- and sesquiterpenes after MeJA application. Besides, irrespective of the MeJA treatment, weevils fed more intensively on Maritime pine than on Monterey pine after the 48- $h$ feeding period.

Chemical analyses demonstrated that MeJA modified differently the total and the individual amounts of volatile terpenes in the two species, with contrasting effects on key monoterpenes that have been reported to affect weevil preferences. In general, more intense responses to MeJA application were observed in Monterey pine, for which total monoand sesquiterpenes were induced and growth rates affected, even at the lower concentrations of MeJA $(5 \mathrm{mM})$. A similar pattern was observed for specific key monoterpenes such as $(+)-\alpha$-pinene and (-)- $\beta$-pinene. The differential inducibility of key monoterpenes between the two pine species may be part of the explanation why pine weevil preference between the two pine species differs in field conditions (where weevils are able to choose where to feed) and in bioassays (in which weevils are forced to feed on one species).

Author contribution statement RZ and LS conceived and designed the experiment, performed the sampling and the bioassays and leaded the analysis of non-volatile resin; LL performed the GC analyses and the statistical analyses, produced the results, wrote the first draft and leaded the writing of subsequent versions of the manuscript; AKBK provided the infrastructure and background for GC-MS analyses of volatile terpenes and helped with the interpretation of the associated data. All authors contributed to revisions and writing of subsequent versions.

Acknowledgements We acknowledge the help of Rocío Campañó, César Cendán and Luz Pato for plant culture, insect rearing and herbivory bioassays. We thank two anonymous reviewers for valuable comments. We also thank David Brown for linguistic revision. This work was performed with funds from the Grants AGL201240151-C03-01 (Compropin Project) and AGL2015 68274-C3-2-R (Futurpin Project) founded by MINECO/FEDER. This work was also financed by the Grant Intramural-CSIC 201640I030 and the Swedish Foundation for Strategic Research no. RBb08-0003 (Parasite Resistant Tree project).

\section{Compliance with ethical standards}

Conflict of interest The authors declare that they have no conflict of interest.

Open Access This article is distributed under the terms of the Creative Commons Attribution 4.0 International License (http://creativeco mmons.org/licenses/by/4.0/), which permits unrestricted use, distribution, and reproduction in any medium, provided you give appropriate credit to the original author(s) and the source, provide a link to the Creative Commons license, and indicate if changes were made.

\section{References}

Björklund N, Nordlander G, Bylund H (2005) Olfactory and visual stimuli used in orientation to conifer seedlings by the pine weevil, Hylobius abietis. Physiol Entomol 30:225-231

Carrillo-Gavilán A, Moreira X, Zas R, Gonzalez-Voyer A, Vilà M, Sampedro L (2015) Phylogenetic and biogeographical patterns in defensive strategies and quantitative allocation to chemical defences in Palaearctic and Nearctic pine trees. J Biogeogr 42:684-693

Conrath U, Beckers GJM, Flors V, García-Agustín P, Jakab G, Mauch F, Newman M-A, Pieterse CMJ, Poinssot B, Pozo MJ, Pugin A, Schaffrath U, Ton J, Wendehenne D, Zimmerli L, Mauch-Mani B (2006) Priming: getting ready for battle. Mol Plant Microbe Interact 19:1062-1071

Fedderwitz F, Nordlander G, Ninkovic V, Björklund N (2016) Effects of jasmonate-induced resistance in conifer plants on the feeding behaviour of a bark-chewing insect, Hylobius abietis. J Pest Sci 89:97-105

Franceschi VR, Krokene P, Christiansen E, Krekling T (2005) Anatomical and chemical defenses of conifer bark against bark beetles and other pests. New Phytol 167:353-375

Heijari J, Nerg AM, Kainulainen P, Viiri H, Vuorinen M, Holopainen JK (2005) Application of methyl jasmonate reduces growth but increases chemical defence and resistance against Hylobius abietis in Scots pine seedlings. Entomol Exp Appl 115:117-124

Heijari J, Blande JD, Holopainen JK (2011) Feeding of large pine weevil on Scots pine stem triggers localised bark and systemic shoot emission of volatile organic compounds. Environ Exp Bot 71:390-398

Howe GA (2004) Jasmonates as signals in the wound response. J Plant Growth Regul 23:223-237

Karban R, Baldwin IT (1997) Induced responses to herbivory. University of Chicago Press, Chicago

Klepzig KD, Schlyter F (1999) Laboratory evaluation of plantderived antifeedants against the pine weevil Hylobius abietis (Coleoptera: Curculionidae). J Econ Entomol 92:644-650

Kovalchuk A, Raffaello T, Jaber E, Keriö S, Ghimire R, Lorenz WW, Dean JFD, Holopainen JK, Asiegbu FO (2015) Activation of defence pathways in Scots pine bark after feeding by pine weevil (Hylobius abietis). BMC Genom 16:352

Långström B, Day KR (2004) Damage, control and management of weevil pests, especially Hylobius abietis. In: Lieutier F, Day KR, Battisti A, Grégoire J-C, Evans HF (eds) Bark and wood boring insects in living trees in Europe, a synthesis. Springer, Dordrecht, pp 415-444

Lewinsohn E, Gijzen M, Croteau R (1991) Defense mechanisms of conifers: differences in constitutive and wound-induced monoterpene biosynthesis among species. Plant Physiol 96:44-49 
Lundborg L, Nordlander G, Björklund N, Nordenhem H, Borg-Karlson A-K (2016) Methyl jasmonate-induced monoterpenes in Scots pine and Norway spruce tissues affect pine weevil orientation. $\mathrm{J}$ Chem Ecol 42:1237-1246

Moreira X, Sampedro L, Zas R (2009) Defensive responses of Pinus pinaster seedlings to exogenous application of methyl jasmonate: concentration effect and systemic response. Environ Exp Bot 67:94-100

Moreira X, Lundborg L, Zas R, Carrillo-Gavilan A, Borg-Karlson AK, Sampedro L (2013) Inducibility of chemical defences by two chewing insect herbivores in pine trees is specific to targeted plant tissue, particular herbivore and defensive trait. Phytochemistry 94:113-122

Nordlander G (1990) Limonene inhibits attraction to $\alpha$-pinene in the pine weevils Hylobius abietis and $H$. pinastri. $\mathrm{J}$ Chem Ecol 16:1307-1320

Nordlander G (1991) Host finding in the pine weevil Hylobius abietis: effects of conifer volatiles and added limonene. Entomol Exp Appl 59:229-237

Nordlander G, Hellqvist C, Johansson K, Nordenhem H (2011) Regeneration of European boreal forests: effectiveness of measures against seedling mortality caused by the pine weevil Hylobius abietis. For Ecol Manag 262:2354-2363

Phillips MA, Croteau RB (1999) Resin-based defenses in conifers. Trends Plant Sci 4:184-190

Sampedro L, Moreira X, Llusia J, Peñuelas J, Zas R (2010) Genetics, phosphorus availability, and herbivore-derived induction as sources of phenotypic variation of leaf volatile terpenes in a pine species. J Exp Bot 61:4437-4447

Sampedro L, Moreira X, Zas R (2011) Resistance and response of Pinus pinaster seedlings to Hylobius abietis after induction with methyl jasmonate. Plant Ecol 212:397-401
Schiebe C, Hammerbacher A, Birgersson G, Witzell J, Brodelius PE, Gershenzon J, Hansson BS, Krokene P, Schlyter F (2012) Inducibility of chemical defenses in Norway spruce bark is correlated with unsuccessful mass attacks by the spruce bark beetle. Oecologia 170:183-198

Schulman E (1954) Longevity under adversity in conifers. Science 119:883-884

Wibe A, Borg-Karlson AK, Persson M, Norin T, Mustaparta H (1998) Enantiomeric composition of monoterpene hydrocarbons in some conifers and receptor neuron discrimination of alpha-pinene and limonene enantiomers in the pine weevil, Hylobius abietis. J Chem Ecol 24:273-287

Zas R, Sampedro L, Prada E, Lombardero MJ, Fernández-López J (2006) Fertilization increases Hylobius abietis L. damage in Pinus pinaster Ait. seedlings. For Ecol Manag 222:137-144

Zas R, Sampedro L, Moreira X, Martins P (2008) Effect of fertilization and genetic variation on susceptibility of Pinus radiata seedlings to Hylobius abietis damage. Can J For Res 38:63-72

Zas R, Moreira X, Sampedro L (2011) Tolerance and induced resistance in a native and an exotic pine species: relevant traits for invasion ecology. J Ecol 99:1316-1326

Zas R, Björklund N, Nordlander G, Cendan C, Hellqvist C, Sampedro L (2014) Exploiting jasmonate-induced responses for field protection of conifer seedlings against a major forest pest, Hylobius abietis. For Ecol Manag 313:212-223

Zhao T, Borg-Karlson A-K, Erbilgin N, Krokene P (2011) Host resistance elicited by methyl jasmonate reduces emission of aggregation pheromones by the spruce bark beetle, Ips typographus. Oecologia 167:691-699 